\title{
DEVELOPMENT OF ANTI-THEFT OFFLINE GPS TRACKER
}

\author{
Sourav Kumar Ghosh ${ }^{1}$, Mamunur Rashid ${ }^{2}$, Nazmus Sama Tuba ${ }^{3}$, Mehbubul Mukaddem Akash \\ Neerjhor $^{4}$, Anika Kader ${ }^{5}$, Tahiya Nuzhat Peata ${ }^{6}$ and Pritom Biswas ${ }^{7}$
}

\author{
1, 2, 3, 4, 5, 6,7 Bangladesh University of Textiles (BUTEX), Tejgaon, Dhaka-1208, Bangladesh.
}

Email: sourav@ butex.edu.bd, mamunrashid@butex.edu.bd, nazmusssama@ gmail.com, akashneerjhor@gmail.com, anika.kader.butex@gmail.com, tahiya.peata@gmail.com, pritombiswas2020@ gmail.com

Received: May $19^{\text {th }}, 2020$

Accepted: Jun $18^{\text {th }}, 2020$

Published: June $30^{\text {th }}, 2020$

Copyright (02016 by authors and Galileo Institute of Technology and Education of the Amazon (ITEGAM).

This work is licensed under the Creative Commons Attribution International License (CC BY 4.0).

https://creativecommons.org/licen ses/by/4.0/

\begin{abstract}
Anti-Theft Offline GPS Tracker has been introduced in this paper to meet up the demand for secure use of important technological gadgets i.e. laptop, mobile phone, etc. It is developed in a way so that if any gadget gets stolen or gets lost, it can track even if it is offline. The tracker will be connected with the battery of the device where it is installed. So, even the device is switched off, it can gain power from the recharged battery from the device. Anti-Theft Offline GPS tracker is designed to locate the place of location offline, of the object with which the GPS Tracker will be attached. It will send a text message containing the Google Map link of the location to a given phone number when asked. By this, the gadget can be identified with its location point. We have followed almost all the procedures of the product development process from getting customer preferences to designing and finalizing the product. Material selection and cost analysis have also been done based on the mass production of the product. This product features exact location \& real-time tracking, quick and continuous reply, rechargeable battery, easy to carry and cost efficient.
\end{abstract}

Keywords: GPS, Arduino, Offline tracking, Real-time response, Product Development.

\section{INTRODUCTION}

Laptops and other portable IT devices i.e. smartphones, tablets, etc. are often lost or stolen frequently nowadays. In a crowded city like Dhaka, stealing laptops and mobile phones is a common issue. However, it is assumed that $98 \%$ of the stolen laptops are hard to be recovered. So, there is a huge economic loss due to this type of crime. Mostly these devices lost or stolen at the airport, other places like shopping malls, left in transport, or even stolen sometime by company employees or other people. One will need to level up his or her security, to prevent this loss of devices, and the information stored within. Stolen IT devices can include proprietary information such as reports, contact lists, important sales-related documents, financial records, and the like. This data can cause great damage if it goes to the wrong hands, such as a competitor or anyone who might want to make a quick buck out of selling the information in the black market. When these devices are stolen, they are immediately turned off and cannot be tracked mostly for being offline. As such, there is a need to protect and track these devices. Understanding the emerging demand of the current scenario, a real-time "Anti-Theft Offline GPS Tracker" can track important devices when it is offline and solve the problems. By doing this, the protection of the devices and the safety of information will be ensured. The product is basically a GPS (Global Positioning System) tracker, made with a micro controller (Arduino Mega) and GSM module and some other equipment to track the devices when they are turned off. We powered our micro controller by a power-bank and our GSM module by a lithium polymer battery. When GPS is fixed, we will automatically receive a message with latitude, longitude, and a Google map link on the number that is given in the Arduino code. The objectives of this paper are stated below.

i. To design the prototype.

ii. To develop a tracker that is easy to carry and that contains a rechargeable battery.

iii. To ensure the security of the device and the valuable information within

iv. To track the exact location of the device.

$\mathrm{v}$. To check the reply from the tracker to the smartphone with a google map link. 


\section{LITERATURE REVIEW}

Among many approaches, the well-known approaches to product design are the systematic approach, axiomatic design, and quality engineering [1]. In the product design phase, everything required to develop a working prototype [2]. Design decisions determine $70 \%$ of product costs and that early design decisions are much more significant than later manufacturing decisions [3]. Huimin Jiang showed in detail that Quality function deployment (QFD) is commonly used in the product planning stage to define the engineering characteristics and target value settings of new products [4]. Hlaing proposed a device where GPS \& GSM have been used for vehicle tracking by installing the device inside a vehicle [5]. Omar developed a Realtime tracking system based on Arduino intel galileo which acts on GPS, GSM, and GPRS which are utilized for vehicle tracking and monitoring. The SIM908 Module is applied which incorporates three technics to be specific GPS, GPRS, and GSM [6]. Dhanya prepared an Anti-Theft Vehicle Tracking System is developed to track vehicles all the time and it can also predict the location of the vehicle if the GPS fails. The Time series prediction algorithm is used for the prediction [7]. Mounika presented vehicle tracking and monitoring using GPS and GSM which is based on the Internet of Things [8]. Poonam implemented a child tracking system using GPS and GSM based on Arduino [9]. Gullipalli proposed a GPS live tracking of buses and fuel monitoring system using Arduino [10]. Kaur developed A smart vehicle designed for mishap location detection, an anticollision system where shock ultrasonic, the temperature sensor is used along with GPS and GSM for real-time analysis [11]. Asianuba designed the anti-theft control system which adopts GSM technology in form of AT command to notify the user through SMS once there is an intruder. It also consists of the inclusion of a database of security agencies so that the SMS is also sent to the nearest security agency [12]. Mohiuddin et al. proposed a smart Anti-Theft vehicle system based on the Internet of Things (IoT) for monitoring the movement of any equipped vehicle from anywhere in real-time. At the implementation of this system, (GPS), (GSM)/ (GPRS) and microcontrollers are used to enable users for monitoring their vehicles in a convenient manner [13]. Paing et al. propose a personal use VAT system using the IoT platform that can be easily introduced due to the very low cost [14]. Light Dependent Resistor (LDR) and motion sensor is used to develop a costefficient automatic street light control system [15]. A low cost solar water purifier is designed and embodied using product development theory [16]. Advanced air purifier facial mask is developed using Arduino Nano and air pump [17].

The tracking system has been mostly using for locating vehicles. There were a few systems for other reasons. But there was no GPS tracking system developed to locate a tech gadget. In daily life, people lose these items. These items get stolen. In order to retrieve these tech gadgets, first we need to know about its location in real-time and that is where our developed product serves its purpose.

\section{METHODOLOGY}

The development of the product starts with the customer survey. Then prioritization of their preferences, develop the quality function deployment (QFD), consist the black box model, analyze the functional decomposition, material and manufacturing process selection, cost analysis, prototype development, testing the prototype and finally the final product is build following all these steps. In figure 1, the full process flowchart is depicted. Customer satisfaction is our main target so that a survey was conducted among people from stages (urban \& rural residential sector) through questionnaires using google response form and face to face interview.

QFD is a process and set of tools used to effectively define customer requirements and convert them into detailed engineering specifications. We converted these customers' needs to technical requirements \& perform QFD (Figure 2).

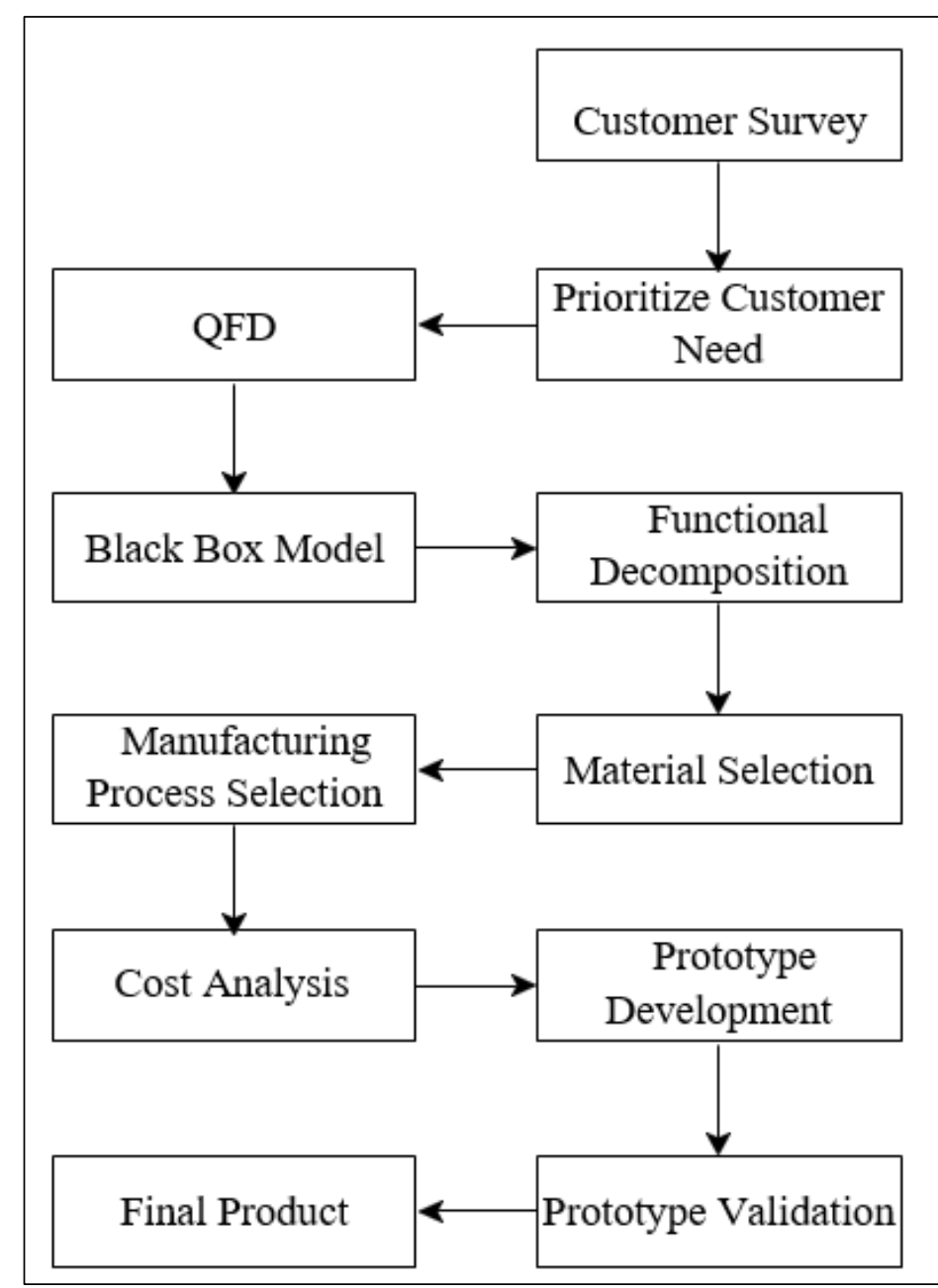

Figure 1: Process flowchart of product development. Source: Authors, (2020).

According to their response, customer needs are classified into three groups that are presented in Table 1.

Table 1: Customer requirements with preference.

\begin{tabular}{|c|l|}
\hline \multirow{4}{*}{$\begin{array}{c}\text { High } \\
\text { Preference }\end{array}$} & Low Cost \\
\cline { 2 - 2 } & Effective Mechanism \\
\cline { 2 - 2 } & Real-time tracking \\
\cline { 2 - 2 } & Device weight \\
\cline { 2 - 2 } Medium & Using for textile purpose \\
\hline \multirow{4}{*}{$\begin{array}{l}\text { Preference } \\
\text { Low }\end{array}$} & The life period of the device \\
\cline { 2 - 2 } & Power supply process \\
\cline { 2 - 2 } Preference & Effortless maintenance \\
\cline { 2 - 2 } & Additional features \\
\cline { 2 - 2 } & Lanufacturing Material \\
\hline & Source: Authors, (2020). \\
\hline
\end{tabular}




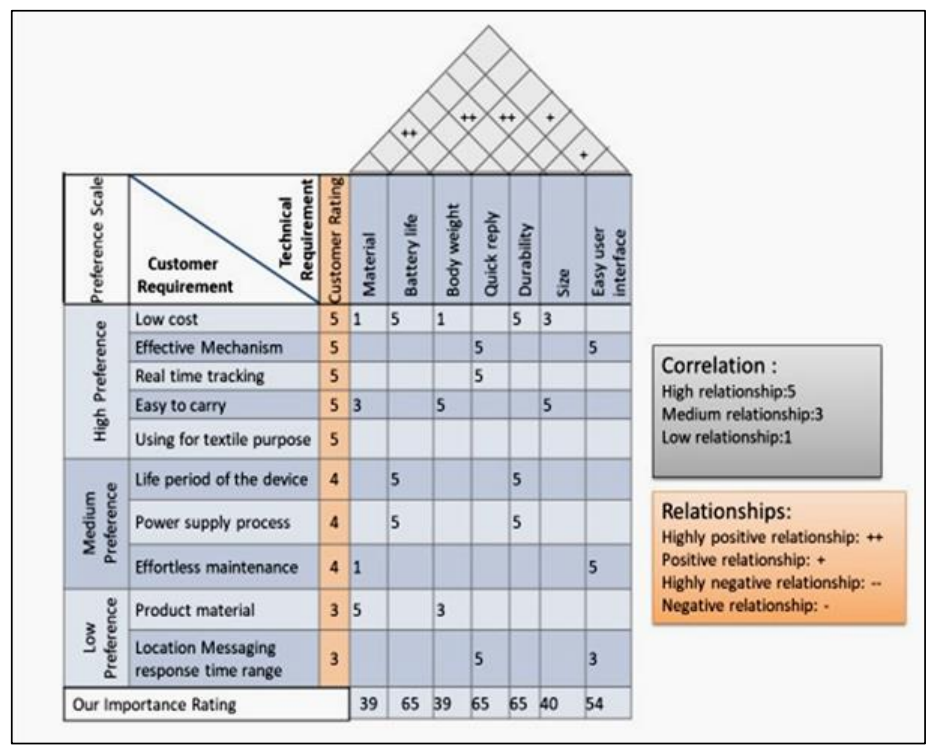

Figure 2: Product Planning Diagram (House of Quality) for AntiTheft Offline GPS Tracker.

Source: Authors, (2020).

From Figure 2 we see that battey life, quick reply \& durability are the main technical requirements for our product. Then we performed functional decomposition where we broke our product into smaller parts. We also conduct a black box design. After planning we have developed the prototype of our product successfully.

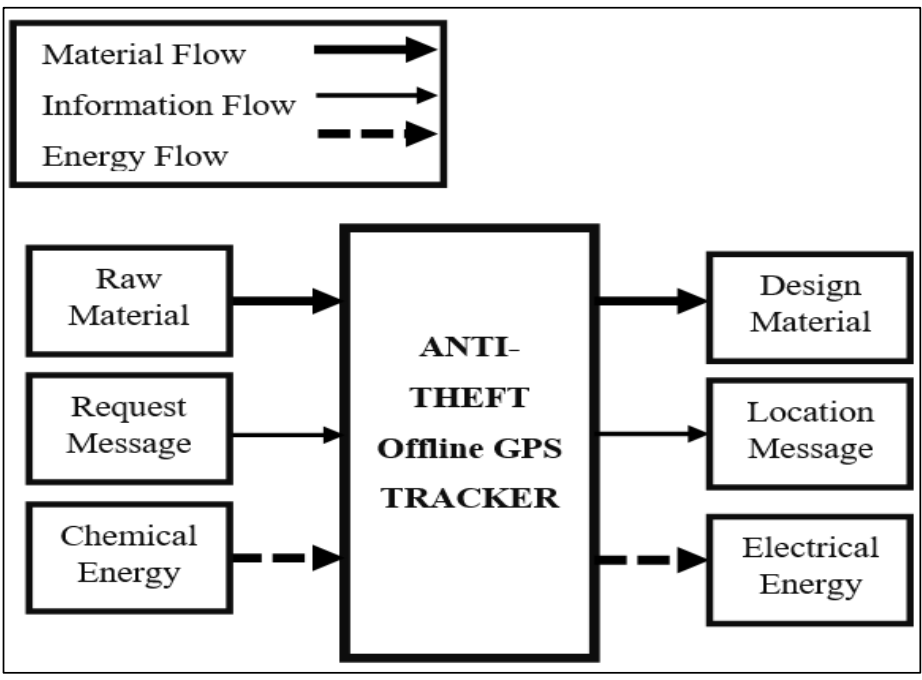

Figure 3: Black Box Model of the Anti-Theft GPS Tracker. Source: Authors, (2020).

From the black box model (Figure 3), we can see that, raw material has been used as an input of raw material \& we got design material as output. Request message has been used as an input of information \& we got location message as output \& chemical energy has been used as an input chemical energy \& we got electrical energy as output from it.

From the cluster function diagram (Figure 4), we see that, chemical energy has been transformed into electrical energy through the energy conversion system which includes mobile battery,9V adapter, Arduino mega \& GSM module. Raw material has been converted to design material using cover, Arduino mega, GSM module, SIM \& connection wire.

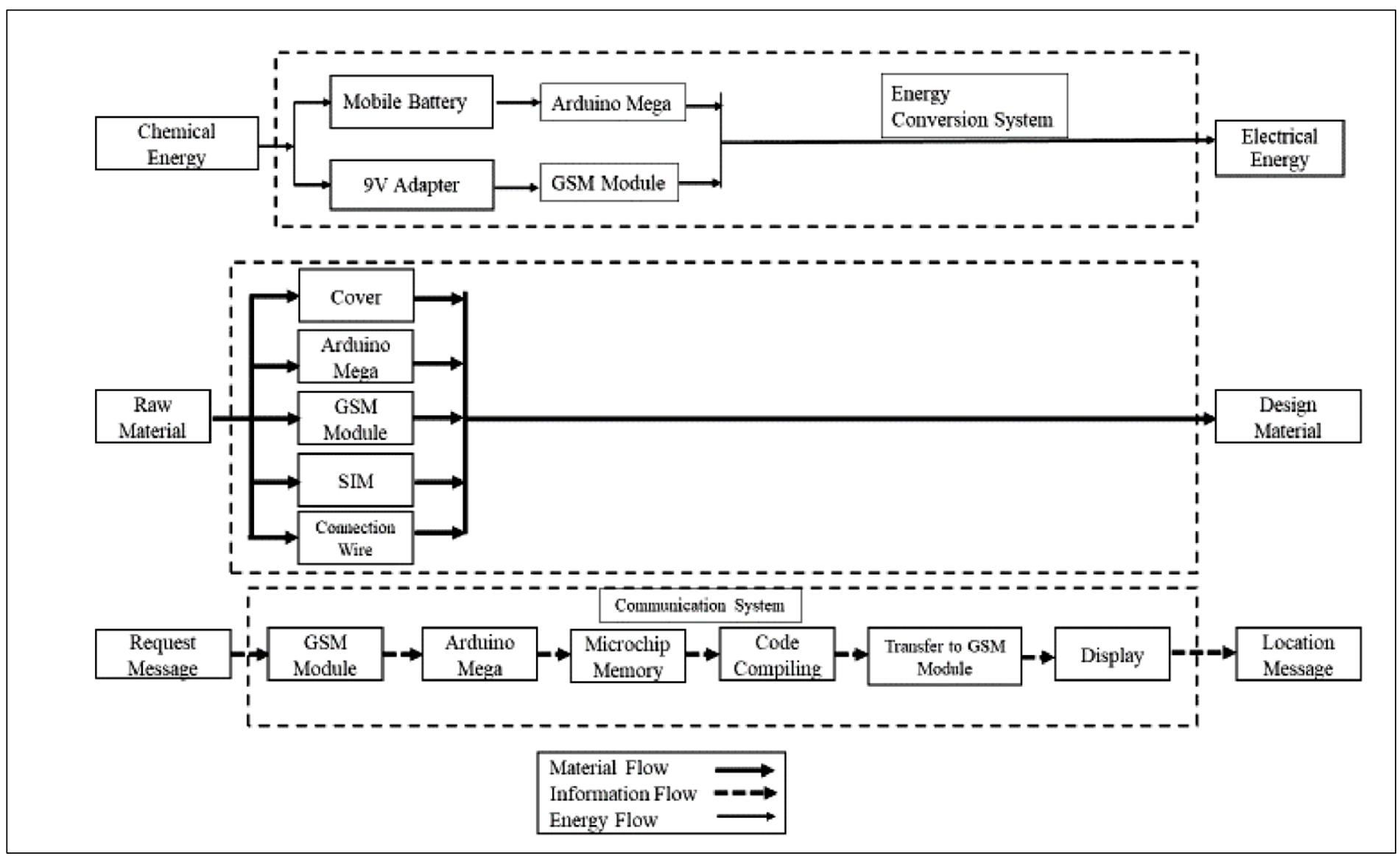

Figure 4: Cluster Function of Anti-Theft GPS Tracker.

Source: Authors, (2020). 
This part mainly built the physical portion of the product which we call hardware system. It also sets up some parts to fulfill the software system implementation by Arduino mega, GSM module, SIM \& connection wire. Request for message has been converted into location message as output through the process of communication system which includes GSM module, Arduino mega, microchip memory, code compiling, transfer to GSM module \& display. After getting a command it goes to GSM module. Then to microchip memory then according to coding it responds with a location reply \& after that it is displayed on the screen. After that material and manufacturing process selection were done by weighted average method. Afterwards the cost analysis was employed, and cost breakdown is shown in Table 2.

Table 2: Cost breakdown for Anti-Theft Offline GPS Tracker.

\begin{tabular}{|c|c|c|c|}
\hline Component Name & Quantity & $\begin{array}{c}\text { Unit Price } \\
\text { (USD) }\end{array}$ & $\begin{array}{c}\text { Total cost } \\
\text { (USD) }\end{array}$ \\
\hline Arduino Mega 2560 & 1 & 7 & 7 \\
\hline GPS Module & 1 & 25 & 25 \\
\hline Battery & 1 & 0.71 & 0.71 \\
\hline 9V Adapter & 1 & 1.77 & 1.77 \\
\hline Jumper wire & 24 & 0.02 & 0.48 \\
\hline SIM & 1 & 0.35 & 0.35 \\
\hline Total & & & 35.31 \\
\hline
\end{tabular}

Source: Authors, (2020).

\section{III.1 HARDWARE SYSTEMS}

1) Arduino Mega 2560: Arduino mega 2560 is a microcontroller board which is based on ATmega2560.It possesses more memory space and me/O pins compared to other boards. There are 16 analog inputs and 4 Hardware serial ports. Tx indicates the transmission of information whereas the RX indicates receive data Power can be connected through DC supply and AC supply. Mega 2560 has a power supply of $3.3 \mathrm{v}$ and $5 \mathrm{v}$. It has a reset button if anyone wants to erase programs or memory. It is helpful for making many automatic machines.

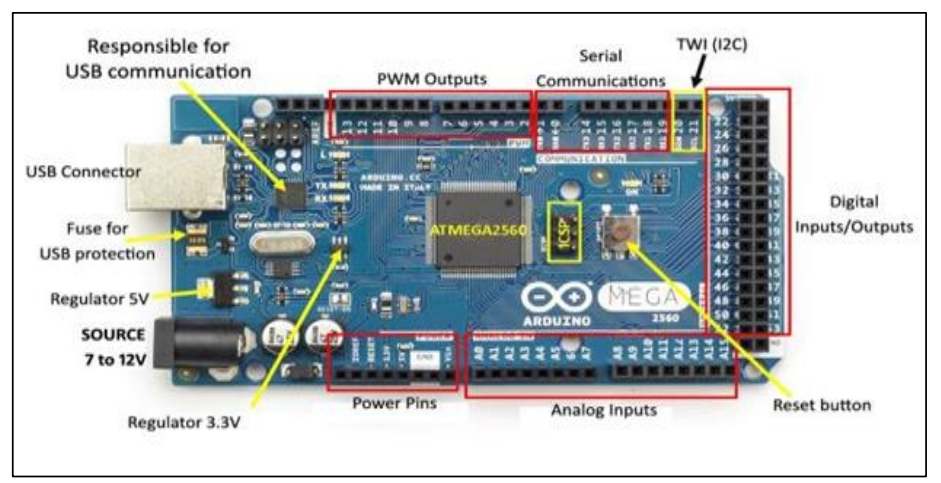

Figure 5: Arduino Mega2560.

Source: Authors, (2020).

2) SIM808 Module: Sim 808 module is $850 / 900 / 1800 / 1900 \mathrm{MHz}$ quad-band GSM/GPRS module. It has a global position system technology for satellite navigation module having internal TCP/IP stack to able to connect with the internet through GPRS. It possesses on board SMA connector for GSM antenna and UFL connector to connect GPS antenna. It has a sim socket including antistatic protection with a micro sim card connector, 3 LEDs to provide module status. SIM 808 module consists of cellular serial ports allows to configure and communicate with GPS receiver for the purpose of calling data for geographical positioning and satellite status through Arduino mega controller. All GPS function is controlled by AT command serial ports.

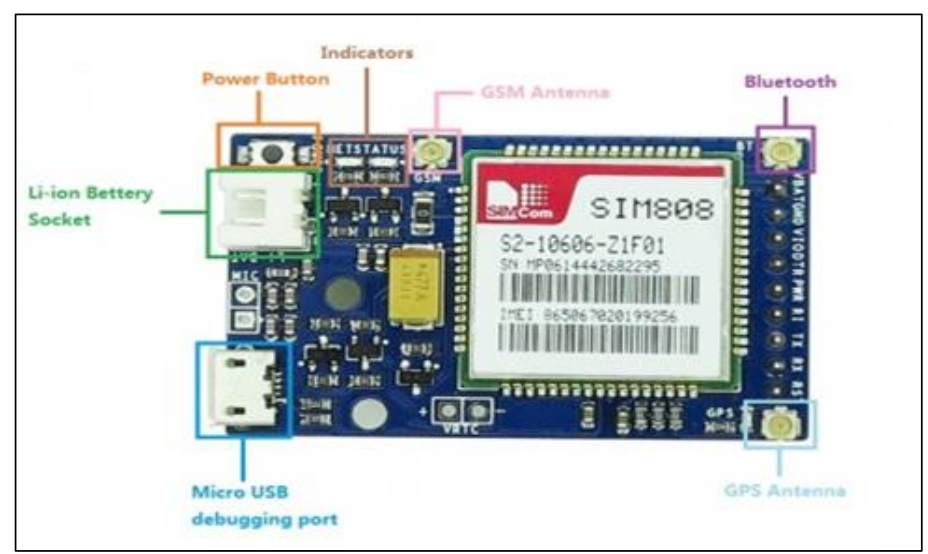

Figure 6: Sim 808 module.

Source: Authors, (2020).

3) GPS Antenna: GPS is a spaced navigation system. It can provide location and time information in all weather conditions. This technology detects latitude and longitude of the position and sends data to the microcontroller (Arduino Mega). Normally it needs three satellites to give exact position. So, for that antenna must be sky facing.

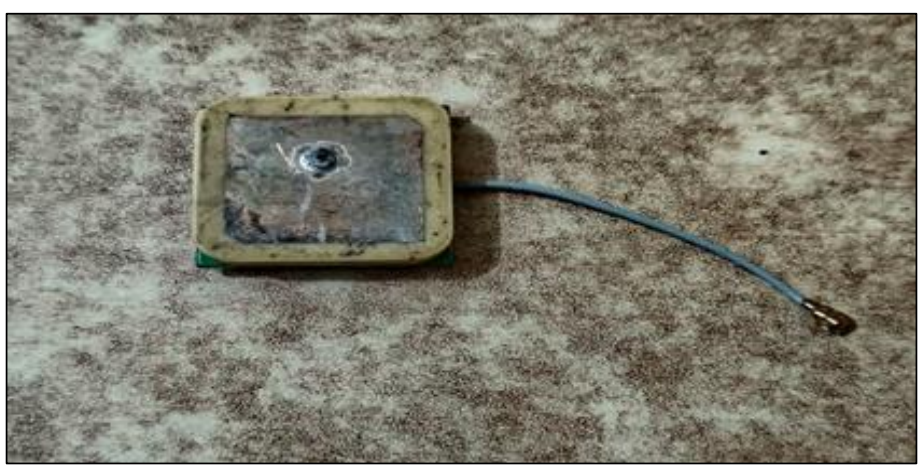

Figure 7: GPS antenna.

Source: Authors, (2020).

4) GSM Antenna: GSM (Global System For Mobile Communication) is a second-generation digital mobile telephone standard using time division multiple access. GSM provides basic to advanced voice and data services including roaming service. GSM antenna is an antenna that transmits GSM signal in a certain frequency of $850,900,1800,1900,2100 \mathrm{MHz}$. GSM antenna boosts the signal strength in receiving and transmitting.

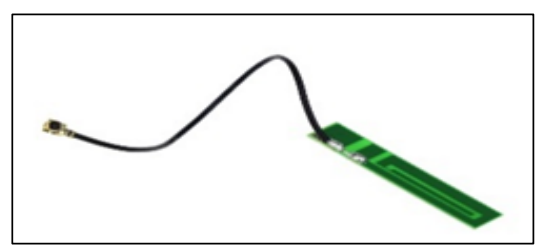

Figure 8: GSM antenna.

Source: Authors, (2020).

5) Battery: A Lithium Polymer battery power of 2200 $\mathrm{mAh}$ is used for the system. It is used to give the system power. 


\section{III.2 SOFTWARE SYSTEM}

1) ARDUINO IDE: IDE stands for "Integrated Development Environment". It is a software introduced by Arduino .cc. It is mainly used for editing, compiling, and uploading the code to Arduino device. Almost all the modules and libraries are compatible with the software. IDE is cross-platform application written in JAVA. It has features such as syntax highlighting, brace matching, and automatic indentation. Arduino IDE comes with a c/c++ library called wiring that helps operations many users friendly. IDE has 2 parts one is Editor and Another one is Compiler.

2) Messages: Messages is an application that is popular among phone users. Android SMS is allows you to receive (SMS) messages and send messages to other phone numbers. Standard carrier rates may apply. This requires the IFTTT app. In the tracking system location is sent to phones through the messages. It contains longitude and latitude

3) Google Maps: Google Maps is a web mapping. It gives us satellite images, street maps, $360^{\circ}$ interactive panoramic views, real-time traffic conditions. It also gives us a route to go from one place to another place. In the tracking system, a link of google Maps is sent so that it becomes easy to find the exact location of the tracker.

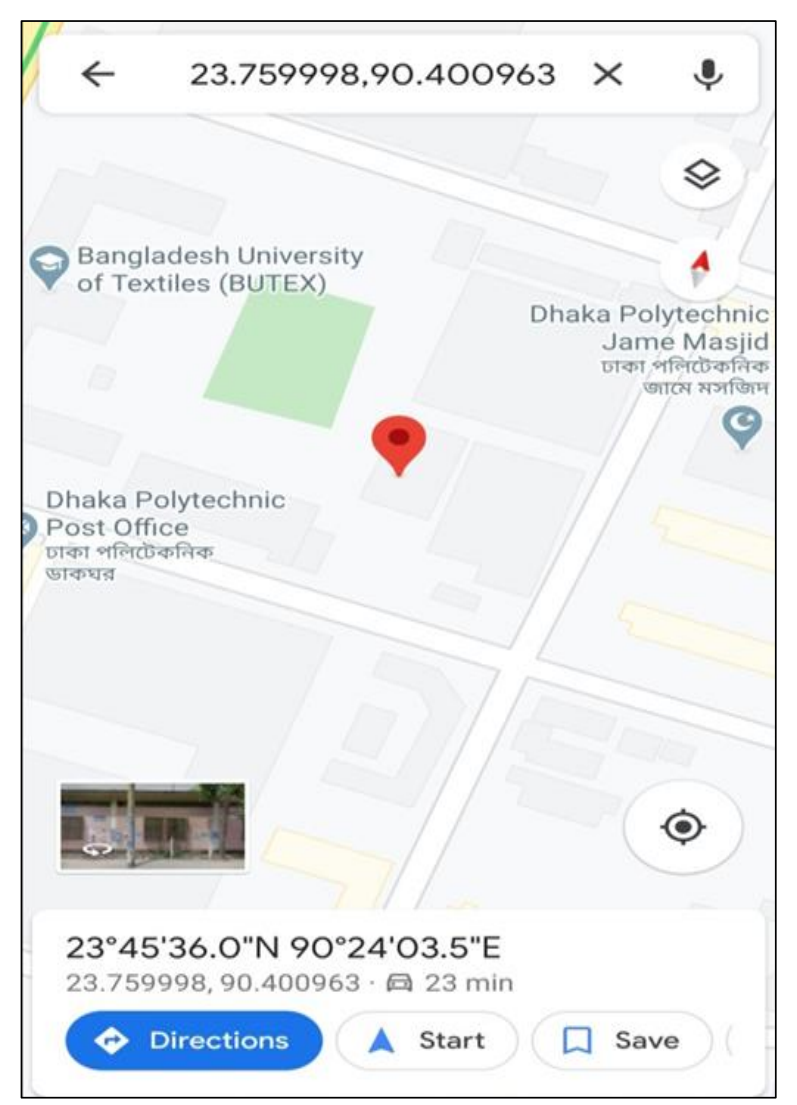

Figure 9: GPS tracking location on Google map. Source: Authors, (2020).

\section{III.2.1 System Implementation}

In the system we have Arduino mega, sim 808 modules, GSM antenna, GPS antenna, and battery. To assemble the system we connect Arduino and sim 808 modules through jumper wires. Those are connected through transmitter pins and receiver pins of the microcontroller and sim 808 modems. GSM antenna and GPS antenna be connected to the GPS and GSM points of the module. After that, we connect battery on the power socket of Arduino Mega. Through the circuit diagram hardware, connections are shown easily.

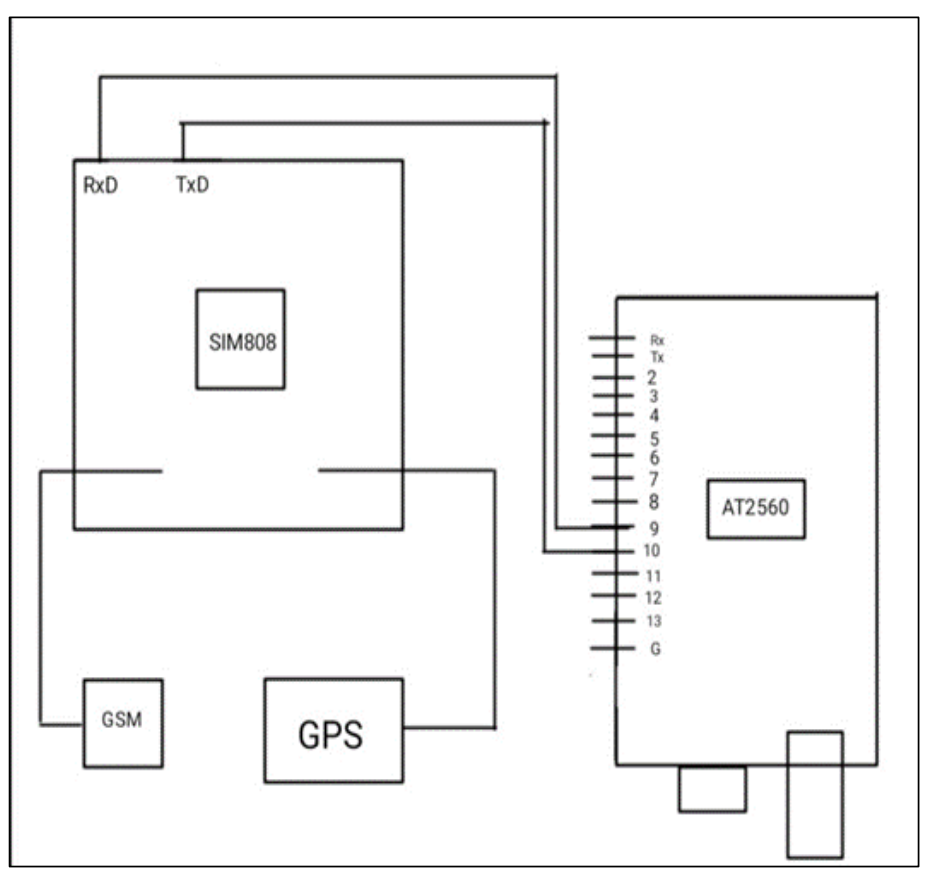

Figure 10: Circuit Diagram of the system. Source: Authors, (2020).

Arduino Ide is the compiler where the code is uploaded to the Arduino mega so that system can run properly. To run the GSM module accurately can need to perform some attention command. GSM is the technology for mobile communication and it is used to connect the computer system over a network cause the GSM module is connected with Arduino. Receiver pin of Arduino is wired with transmitter pin of sim 808 modems. and transmitter pin of Arduino is wired with the receiver pin of sim 808 modems. Both are attached to the modem's shield. System needs attention command for selecting a mode for transfer and receive messages.

Table 3: Command information.

\begin{tabular}{|c|c|}
\hline Command & Purpose \\
\hline AT+CMGF & Text Mode \\
\hline AT+CMGS & Send Message \\
\hline AT+CMGD & Delete Message \\
\hline AT+CMGSS & Send stored Message \\
\hline AT+CMGA & Answer the call \\
\hline
\end{tabular}

Source: Authors, (2020).

After compiling the program, the system is ready to go. So, regarding knowing the position we need to call or send a message to the sim located to the module. After that the GPS antenna will try to connect three satellites to give position After connecting with three satellites it will reply with the longitude and latitude value and google links to the person's phone. Anyone can see the location of the system by inputting longitude and latitude on converter or google map link. Smartphone users can use google map to see the location after clicking the Gmap link. GPS receiver measures the distance between itself and the satellite. Receiver also measures time means exactly how long it takes each satellite's message to arrive. In this process, anyone can know the location. 


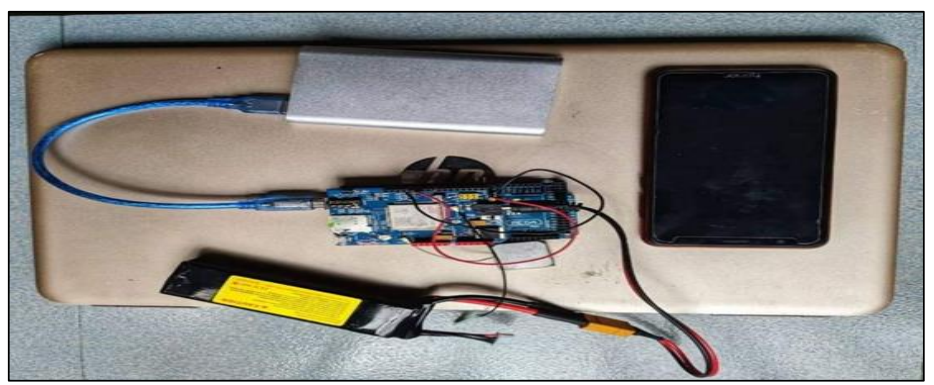

Figure 11: Anti-theft offline GPS tracker. Source: Authors, (2020).

\section{CONCLUSION}

The main aim of developing this product is to track technological gadgets when they are in offline mode. A command will be sent asking for the location of the device through SMS or phone call $\&$ the system will reply with its location in the form of longitude \& latitude and link of Google map to a given phone number. The response will come shortly after command with real time location. It will help to retrieve lost or stolen devices that occurs almost every day in our lives.

Now we have developed a prototype of the product. In future this product can be modified heavily. Products shape and size can be manipulated for this usage of nano technology can be implemented. A high powerful GPS tracker will increase location accuracy. Response time can be accelerated. For location storage cloud system can be implemented. In future it can be useful for all types of tech gadgets and precious items. Further development will also decrease its price which will make it an affordable product.

\section{REFERENCES}

[1] S. Yamaguchi and H. Morita, "Efficient product design using functional equations," Journal of Advanced Mechanical Design, Systems and Manufacturing, vol. 12, no. 6, pp. 1-12, 2018, doi: 10.1299/jamdsm.2018jamdsm0114.

[2] M. A. Levin, T. T. Kalal, and J. Rodin, "Product Design Phase," Improving Product Reliability and Software Quality, pp. 273-297, 2019, doi: 10.1002/9781119179429.

[3] J. A. Barton, D. M. Love, and G. D. Taylor, "Design determines $70 \%$ of cost? A review of implications for design evaluation," Journal of Engineering Design, vol. 12, no. 1, pp. 47-58, 2001, doi: 10.1080/09544820010031553.

[4] H. Jiang, C. K. Kwong, and X. G. Luo, "Intelligent Quality Function Deployment," Intelligent Decision Making in Quality Management, vol. 97, pp. 327-362, 2016, doi: 10.1007/978-3-31924499-0_11.

[5] N. N. S. Hlaing, M. Naing, and S. S. Naing, "GPS and GSM Based Vehicle Tracking System," International Journal of Trend in Scientific Research and Development, vol. 3, no. 4, pp. 271-275, 2019, doi: 10.31142/ijtsrd23718.

[6] O. A. Mohamad, R. T. Hameed, and N. Țăpuş, "Design \& implementation of real time tracking system based on Arduino Intel Galileo," in Proceedings of the 8th International Conference on Electronics, Computers and Artificial Intelligence, Ploiesti, ROMÂNIA., 2017, doi: 10.1109/ECAI.2016.7861114.
[7] N. M. Dhanya, "Anti-Theft Vehicle Tracking System using GPS and Location Prediction," International Journal on Advanced Science, Engineering and Information Technology, vol. 8, no. 6, pp. 2584-2589, 2018, doi: 10.18517/ijaseit.8.6.2847.

[8] A. Mounika and A. Chepuru, "IoT based vehicle tracking and monitoring system using GPS and GSM," International Journal of Recent Technology and Engineering, vol. 8, no. 2 Special Issue 11, pp. 2399-2403, 2019, doi: 10.35940/ijrte.B1275.0982S1119.

[9] P. Patel, S. K. Rauniyar, T. Singh, B. Dwivedi, and P. H. Tripathi, "Arduino Based Child Tracking System Using GPS and GSM," International Research Journal of Engineering and Technology (IRJET), vol. 5, no. 3, pp. 4137-4140, 2018.

[10] S. Gullipalli, Y. Karri, and S. Kota, "GPS Live Tracking of Buses and Fuel Monitoring System using Arduino," International Journal for Research in Applied Science and Engineering Technology, vol. 6, no. 3, pp. 2278-2285, 2018, doi: 10.22214/ijraset.2018.3362.

[11] P. Kaur, A. Das, M. P. Borah, and S. Dey, "Smart Vehicle Safety System Using Arduino," ADBU Journal of Electrical and Electronics Engineering (AJEEE), vol. 3, no. 1, pp. 20-25, 2019, [Online]. Available: www.tinyurl.com/ajeee-adbu.

[12] I. B. Asianuba and R. O. Okeke, "Gps/Gsm Technology for Anti-Theft Control System," American Journal of Engineering Research (AJER), vol. 7, no. 10, pp. 189-195, 2018, [Online]. Available: www.ajer.org.

[13] M. S. Uddin, M. M. Ahmed, J. B. Alam, and M. Islam, "Smart Anti-Theft Vehicle Tracking System for Bangladesh based on Internet of Things," in 4th International Conference on Advances in Electrical Engineering, Dhaka, Bangladesh., 2017, pp. 624-628, doi: 10.1109/ICAEE.2017.8255432.

[14] S. Paing, M. Oo, M. Othman, and N. Funabiki, "A Personal Use Vehicle Anti-Theft Tracking System Using IoT Platform," International Journal of Computer \& Software Engineering, vol. 4, 2019, doi: 10.15344/2456-4451/2019/141.

[15] M. S. Ahmmed, T. Z. Chowdhury, and S. K. Ghosh, "Automatic Street Light Control System using Light Dependent," Global Journal of Research In Engineering, vol. 18, no. 1, 2018, [Online]. Available: https://engineeringresearch.org/index.php/GJRE/article/view/178 1 .

[16] S. K. Ghosh, M. Rashid, N. Zoha, F. K. Torsha, and I. Z. Era, "Development of A Low- Cost Solar Water Purifier Using Metaheuristic Process," in 10th International Conference on Industrial Engineering and Operations Management, Dubai, UAE., 2020, pp. 1268-1277.

[17] M. Rashid, S. S. Tushan, and S. K. Ghosh, "Development of Portable Electromagnetic Radiation Protective E-Textile," in 10th International Conference on Industrial Engineering and Operations Management, Dubai, UAE., 2020, pp. 337-344. 